phorescence spectrum given by a mixture of $6 \mathrm{I}$ parts yttrium and 39 parts of samarium, and illustrated it by a colourec lithograph. Also in a paper read before the Royal Society, February 25, 1886 (Roy. Soc. Proc. vol. xl. p. 236), I described and figured the phosphorescent spectrum of an earth obtained in the fractionation of yttria which was identical, chemically and spectroscopically, with an earth discovered by M. de Marignac, and provisionally called by him $\mathrm{Ya}$. I repeat here these spectra, and the spectrum of yttrium added for comparison. Omitting minor details, it is seen that the $\mathrm{Y} a$ spectrum is identical with

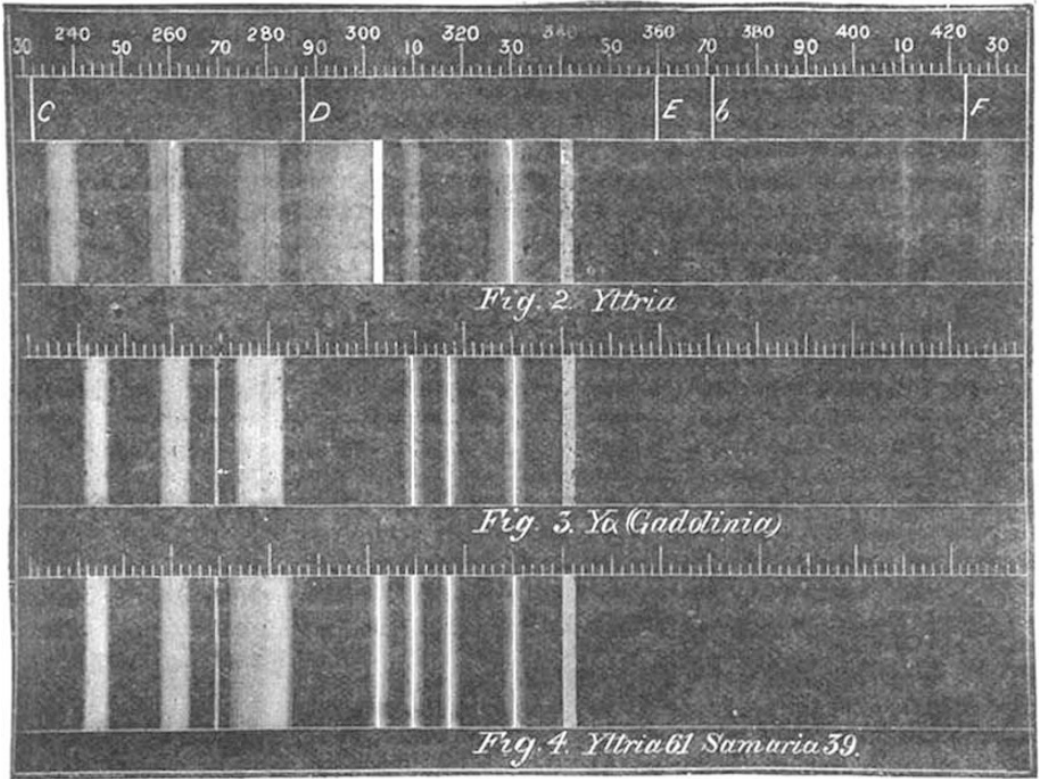

that of the mixture yttrium $6 \mathrm{I}$, samarium 39 , with one important exception-the citron line of G $\delta$ in the former spectrum is absent in the latter. Could I by any means remove Go from the mixture of yttrium and samarium the residue would be $\mathrm{Ya}$. I have little doubt that this will soon be accomplished, but in the meantime the phosphoroscope enables us to remove the line of GS from the mixture. It is only necessary to add strontium to a suitable mixture of yitrium and samarium and view the phosphorescing mixture in the instrument when the wheel is rotating rapidly, to obtain a spectrum which is indistinguishable from that of Y $\boldsymbol{\alpha}$.

(To be continued.)

\section{PRE-SCIENTIFIC THEORIES OF THE CAUSES OF EARTHQUAKES}

I $\mathrm{N}$ the course of a lecture delivered recently before the Rigaku Kyôkai, or Science Society of Tokio, on the causes of earthquakes, Prof. Milne classified the theories as to the cause of these phenomena into three kincls-unscientific, quasi-scientific, and scientific. In the former class he included the explanations of the Negro preachers at Charleston after the late earthquakes there, that they occurred in consequence of the wickedness of the population. The Mussulmans in Java recently prayed to the volcanoes there to cease their shakings, at the same time promising reformation of life. That earthquakes are the direct result of man's wickedness is an idea that has always been common. About I 750 earthquakes were felt in many parts of Europe, which were widely attributed to this cause, and in numerable sermons were preached inculcating the lesson that if mankind would live better lives there would be no more earthquakes. In 1786, after a shock at Palermo, the people are recorded to have gone about scourging themselves, and looking extremely humble and penitent. An English poem called "The Earthquake," published in $175^{\circ}$, alleged, in somewhat halting verse, that the disturbances were not due to an unknown force, nor to the groanings of the imprisoned vapours, nor yet to the shaking of the shores with fabled Tridents :-

"Ah no! the tread of impious feet

The conscious earth impatient bears

And shuddering with the guilty weight,

One common grave for her bad race prepares."

From this theory, which can scarcely have satisfied the poet himself, Prof. Milne passed on to the myths which attribute earthquakes to a creature living underground. In Japan it is an "earthquake-insect" covered with scales, and having eight legs, or a great fish having a certain rock on his head which helped to keep him quiet. In Mongolia the animal was said to be a froz, in
India the world-bearing elephant, in the Celebes a world-supporting hog, in North America a tortoise. In Siberia there was a myth, connected with the great bones found there, that these were the remains of animals that lived underground, the trampling of which made the ground shake. In Kamchatka the legend was connected with a god, Tuil, who went out hunting with his dogs. When these latter stopped to scratch themselves, their movements produced earthquakes. In Scandinavian mythology, Loki, having killed his brother Baldwin, was bound to a rock face upwards, so that the poison of a serpent should drop on his face. Loki's wife, however, intercepted the poison in a vessel, and it was only when she had to go away to empty the dish that a few drops reached him and caused him to writhe and shake the earth. The lecturer had no means of collecting the fables of the southern hemisphere; but they would obviously be worth knowing for purposes of comparison. As to quasiscientific theories, these endeavoured to account for earthquakes as parts of the ordinary operations of Nature. It was supposed, for instance, that they were produced by the action of wind confined inside the earth. The Chinese philosophers said that Yang, the male element, entered the earth and caused it to expand, and to shake the ground in its efforts to escape. Its effects would be more violent beneath the mountains than in the plains, and therefore earthquakes in the north of China, which was mountainous, were said to be more violent than those in the south. It was supposed that when the wind was blowing strongly on the surface of the earth, there was calm beneath, and vice vers $\hat{x}$. Aristotle and many other classical writers attributed earthquakes to wind in the earth. Shakespeare, in "Henry IV.," speaks of the teeming earth being pinched and vexed with a kind of colic by the imprisoning of unruly wind within her womb. Then came the theory of electrical discharges, which was advocated in 1760 by Dr. Stukely, as well as by Percival and Priestley. They are strongly held in California at the present day, where it was believed that the network of rails 
protected the State against any dangerous accumulation of electricity. But Prof. Milne showed that the laying down of raiks in Japan had no such effect. He thought the electric plrenomena which sometimes attended earthquakes were their consequences, not their causes. He had himself experimented with dynamite placed in a hole ; an earth-plate was fixed about thirty yards away from the dynamite, and from it a wire was carried some distance to another earth-plate. When the dynamite charge was exploded there was certainly a current produced, as was indicated by a strong deflection of a galvanometer-needle at the end of the wire. He attributed this to chemical action. When the ground was shaken there was always a greater or less action by increase or decrease of pressure in connection with the earthplate. Earth currents unquestionably accompany earthquakes, but, as has been said, they appear to be the consequences, not the causes, of the latter. Next came the chemical theories, which were very strong in Europe up to the beginning of the present century. It was imagined that underground there were various substances, such as sulphur, nitre, vitriol, which, by their action on each other, resulted in violent changes, giving rise to vapour, the sudden production of which, in certain cases, would shake the ground. It was only in I760 that Dr. Mitchell, who wrote a good deal on the subject, first threw out the theory that earthquakes were connected in some way with volcanoes, because they were most frequent in volcanic countries. He observed that large quantities of steam were given off from volcanoes, and came to the conclusion that an earthquake was produced at the time that an attempt was made to form a volcano, that steam got in between certain strata, and, as it ran between them, caused pulsations. Prof. Rogers, about the same time, in North America, endeavoured to show that it was not steam, but really lava, that ran along underneath the ground, causing it to rise and fall, thus producing an earthquake. Prof. Milne having thus dealt with unscientific and quasi-scientific theories, passed on to those of modern science. It is unnecessary here to follow him into this portion of his subject, although it occupied the main part of the lecture.

\section{ON THE EFFECT OF CERTAIN STIMULI ON VEGETABLE TISSUES ${ }^{1}$}

THE object of our paper is to clescribe the behaviour of turgescent pith when placed in water and treated with certain reagents. If from a growing shoot the external tissues be removed, a well-known result is seen : the pith suddenly lengthens, becoming longer than the specimen was at first. This experiment shows that turgescent pith is normally in a compressed condition-it is always trying to get longer-and when it is freed from the coercion of the unyielding external tissues, it at once does become longer. This tendency to become longer is further manifested by allowing turgescent pith to remain in damp air, or in water, for some time, when a great increase in length takes place. In such a piece of pith we have the essential, active factor in growth, freed from interference, and at liberty to perform its function rapidly and freely. The tendency in turgescent pith to get longer is the very power which calls forth that increase in length which we call growth; so that in studying turgescent pith we are studying the active agent in the production of growth. We do not suppose that our results are necessarily dircctly applicable to normal growth, ${ }^{2}$ but we think that they have a bearing on normal growth sufficiently close to give interest to our experiments.

The pith, ${ }^{3}$ after being cut into pieces about 6 inches in length and $\frac{1}{3}$ inch in thickness, was ready for use. The lower end of the pith was fixed to a hook at the bottom of a narrow jar, the upper end was attached by a silk thread to the short arm of an auxanometer lever. The jar was then filled with water, and as the pith elongates the short arm of the lever ascends and the long arm rapidly descends. Its movement, read off on a millimetre scale, gives an index of the rate of "growth" of the pith. The lengthening of the pith is, in fact, observed like the normal srowth of a plant, the only difference being that the "growth" of the pith is so rapid that the descent of the long arm is clearly visible to the naked eye and is correspondingly easy to measure. It is most striking to see the index travelling down thus quickly

${ }^{I}$ Abstract of a Paper by Anna Bateson (Newnham College) and Francis Darwin (Cambridge), read before the Linnean Society, January 20, 1887 . ${ }^{2}$ For the sake of convenience we shall nevertheless use the word "growth" to mean the elongation of the pith under observation.

3 Sunflower and Jerusalem Artichoke. and traversing (it may be) $10 \mathrm{~mm}$. ( $\frac{2}{5}$ inch) in a minute. Wo used a stop-watch to determine the time in which the point of the long arm of the lever travelled over a certain distance, and we could thus estimate the changes in the rate of growth from minute to minute.

The first thing needful to know is the ordinary course of growth of the pith in water. It was found that an interesting phenomenon-an apparent grand period-takes place. That is to say, the growth is at first slow, then more rapid, and ultimately becomes slow again, the whole period taking perhaps twenty minutes to complete. This is preciscly the series of changes which a growing organ exhibits in the course of days instead of minutes. We do not suppose that our grand period is necessarily of a kindred nature to the grand period of normal growth. For we are aware that purely mechanical processes, such as the moistening of a hygroscopic awn, exhibit the same thingthe awn at first untwists slowly, then more quickly, and then again slowly. But the knowledge of the fact is of great importance to us, since unless we know the normal course of growth we cannot study the effect of reagents.

Warmth.-Before going on to consider the action of reagents, we will say a few words as to the stimulation caused by an increase in the surrounding temperature. If the water in the jar is gradually warmed, the growth of the pith increases in specd in the most striking manner. The increase is fairly steady from, say, $17^{\circ} \mathrm{C}$. to about $35^{\circ}$, the rate at this latter tempera. ture being perhaps four times as high as it was at first. It then usually becomes irregular, with some diminution; and, just before a temperature is reached which kills the tissues, a sudden and rapid fall in the rate of growth sets in. This we found usually to occur at about $55^{\circ} \mathrm{C}$. This is, no doubt, an unusually high temperature, but not higher than plants are known to be able to survive.

The chief interest in these temperature experiments is this they show that the phenomena we are considering is a truly vital one. We have always been on our guard in this matter, and have wished to make certain that the observed phenomena are not in some mysterious way mechanical, instead of, as we believe, the response of living tissues as living tissues. Therefore, when we find that heat has a normal effect on our material we are encouraged to believe that our other results-to which we now pass on-are also vital phenomena.

Alcokol.-The pith was attached to the auxanometer, and the jar filled with water. As soon as the rate of growth was found to be steadily diminishing, a small quantity of alcohol was added. The result was an immediate and striking increase in the rate of growth. For instance, when 2 per cent. of spirit was added, the growth was accelerated within two minutes by 50 per cent.

The result is temporary, so that in the course of another two minutes the rate of growth sinks to what it was before stimulation. Similar results were obtained with ether, and here the pith was allowed to grow in damp air, and was subjected to ether in the form of vapour. When the vapour was present in the proportion of $0^{\circ} 27$ per cent., the acceleration was $5^{6}$ per cent. with 0.4 per cent., the acceleration was Ioo per cent, Here, as in the case of alcohol, the result was temporary, the rate falling in a few minutes to what it was before stimulation.

When the ether amounts to 3 per cent. of the atmosphere, the pith is killed, and shows no increase, but, on the contrary, a decrease ${ }^{1}$ in length. Elfving has shown that ether has a stimulating effect on respiration, and on the sensitiveness of swarm-spores to light. He also tested its effect on the growth of phycomyces. IIis results differ from ours, inasmuch as he found no stimulating effect : the ether produced either no effect whatever, or else it retarded, or even stopped, growth.

Ammonia. - We employed the Liquor Ammonia fortior of the "British Pharmacopeia" for the preparation of our solutions, and we found that various strengths ranging between 0.5 and 2.4 per cent. produced acceleration of growth. Here again, as with ether and alcohol, the acceleration was very temporary.

Acids.-As a rule, acids produced no acceleration, but caused either retardation, or flaccidity and death. Thus, for instance, acetic acid ( 0.5 and I per cent.) produced retardation ; 5.4 per cent. produced death.

Hydrocyanic Acid did not cause flaccidity such as we have described in the case of acetic acid. The action of this reagent is comparable rather to that of alcohol, but is not

I This contraction is simply a symptom of flaccidity, and usually of death. 